\title{
Bilgisayar Destekli Teknik Tasarım Dersleri İçin Açık Kaynak Kodlu Müfredat Önerisi
}

\author{
Fahri Anıl Selçuk ${ }^{\mathrm{a},}$, Aydın Tarık Zengin ${ }^{\mathrm{b} *}$, \\ a Marmara Üniversitesi, Fen Bilimleri Enstitüsü, Mekatronik Mühendisliği Bölümü, İstanbul, Türkiye \\ b İstanbul Sabahattin Zaim Üniversitesi, Mühendislik ve Doğa Bilimleri Fakültesi, Bilgisayar Mühendisliği Bölümü, İstanbul, Türkiye
}

İstanbul Sabahattin Zaim Üniversitesi Fen Bilimleri Enstitüsü Dergisi (2021) 3 (1): $26-29$

https://doi.org/10.47769/izufbed.876248

(iD) ORCID ${ }_{1}^{1} 0000-0002-0084-6212 ;{ }^{2}$ 0000-0002-0860-4509

\begin{tabular}{l}
\hline YAYIN BİLGİSI \\
\hline Yayın geçmişi: \\
Gönderilen tarih: 7 Şubat 2021 \\
Kabul tarihi:17 Şubat 2021 \\
\hline Anahtar kelimeler: \\
Teknik Resim \\
Bilgisayar Destekli \\
Tasarım(CAD) \\
Eğitim
\end{tabular}

\begin{tabular}{l} 
ÖZET \\
\hline Günümüz dünyasında kullanımı gün geçtikçe artan açık kaynak kodlu yazılımlar, endüstride olduğu gibi \\
eğitim alanında da sıklıkla kullanılmaktadır. Kolayca erişilebilmesi, kullanıcılar tarafından sürekli \\
geliştirilmesi ve kullanım kolaylığı gibi sebepler açık kaynak kodlu yazılımları eğitim alanında tercih \\
edilen bir unsur olarak öne çıkarmaktadır. Bu çalışmada, açık kaynak kodlu FREECAD yazılımı \\
kullanılarak, çeşitli mühendislik ve ön lisans programlarında bulunan Bilgisayar Destekli Teknik Tasarım \\
dersi için bir müfredat önerisi hazırlanmıştır. Hazırlanan müfredat önerisi ve müfredatın FREECAD de \\
kullanımı incelendiğinde, yazılımın eğitim kurumlarında da rahatlıkla kullanılabilir olduğu görülmektedir.
\end{tabular}

\section{Open Source Curriculum Proposal For Computer Aided Technical Design Courses}

\begin{tabular}{l}
\hline ARTICLE INFO \\
\hline Article history: \\
Received: 7 February 2021 \\
Accepted: 17 February 2021 \\
\hline Key words: \\
Technical Drawing \\
Computer Aided Design(CAD) \\
Education
\end{tabular}

\section{Giriş}

Günümüz dünyasında hızla gelişen teknoloji ile beraber bilgiye erişim de gittikçe kolaylaşmıştır. Bilgiye erişimin kolaylaşması, açık kaynak kodlu yazılımların ortaya çıkması ile daha da ön plana çıkmıştır. Gün geçtikçe daha da gelişen açık kaynak kodlu yazılımlar sebebiyle, sektördeki ücretli yazılımların yerini almaya başlamıştır. Ayrıca kullanıcısına yazılımı dilediği gibi modifiye etme imkanı da veren açık kaynak kodlu yazılımlar, bu yönü ile kullanım penceresini oldukça genişletmektedir (GNU, ty). Gerek mühendislik gerek de sosyal bilimler alanındaki neredeyse tüm sektörlerde açık kaynak kodlu yazılımların kullanımı oldukça yaygınlaşmıştır Eklemeli imalatın (Additive Manifacturing) kullanımının yaygınlaşması ile beraber 3 boyutlu yazıcılar oldukça yaygınlaşmıştır. Açık kaynak kodlu yazılımlarda da kullanılabilen 3 boyutlu yazıcılar, eklemeli imalat süreçlerini hızlandırarak maliyet avantajı sağlamış ve prototip geliştirmeyi son kullanıcı düzeyinde yapılabilir hale getirmiştir (Pearce ve ark., 2010).

3 boyutlu yazıcılar, yalnızca ev tipi kullanıcılar değil imalat sanayinde de kullanılmaktadır. 3D yazıcıların artan kullanımı, küçük üretici ve ev tipi üretim yapan kullanıcıları Bilgisayar Destekli Tasarım ( Computer Aided Design / CAD ) yazılımlarını kullanmaya itmiştir. Açık kaynak kodlu CAD yazılımları, hem eğitim dokümanlarına erişimin kolaylığı, hem de ücretsiz olmaları sebebi ile küçük üretici ve ev tipi kullanıcılar tarafindan oldukça tercih edilmektedir (Pearce ve ark., 2010; Junk ve Kuen, 2016).

Sağlık alanında da oldukça fazla kullanılmaya başlanan 3d yazıcılar ile beraber açık kaynaklı CAD yazılımları, vücut ya da diş protezleri gibi yüksek maliyetli ürünlerin çok daha ekonomik bir şekilde imal edilebilmesine olanak sağlamaktadır (Fang-Yu ve ark., 2019; 
Vasques ve ark., 2019).

Açık kaynak kodlu CAD yazılımlarının kullanıldığı alanlardan biri de elektromekanik sistemlerdir. Küresel ısınmanın dünyanın geleceği üzerindeki etkilerinin ne kadar önemli olduğunun anlaşılması sonucunda insanların kendi evlerinde enerji ihtiyacını gidermek için yenilenebilir enerji kaynaklarını kullanma eğilimi gün geçtikçe artış göstermektedir. Yenilenebilir enerji kaynaklarını kullanan elektromekanik sistemlerin tasarımında ve analizinde, açık kaynak kodlu CAD yazılımları kullanılarak, hem sistemin tasarımı, hem de tasarımı yapılan sistemin analizleri yapılabilmektedir (Tachibana ve Oka, 2011).

Nükleer fizik alanında ise, parçacık hızlandırıcı(Accelator Driven System) gibi hayati parçaların tasarımında, açık kaynak kodlu CAD programları kullanılabilmektedir (Jin-Yang ve ark., 2018). Hayati öneme sahip bu elemanların tasarımında açık kaynak kodlu sistemlerin kullanılabilmesi, yazılımların güvenilirliği ve kullanılabilirliği konusunda çok ciddi örneklerdir.

$\mathrm{Bu}$ çalışmada, açık kaynak kodlu CAD yazılımlarının, eğitim alanında aktif olarak kullanılabilirliği üzerinde bir öneri olarak sunulacaktır. Bilgisayar Destekli Tasarım dersleri, mühendislik eğitimde oldukça büyük öneme sahiptir. Tasarım esnasında malzeme seçimi, imalat yöntemi ve malzemenin dayanımı gibi birçok parametre değerlendirilmelidir (Robertson ve Allen, 1991). Ayrıca Bilgisayar Destekli Tasarım programları, mühendislik öğrencileri için en iyi öğrenme sistemlerinden biri olan proje tabanlı öğrenme (Project based learning) sisteminde büyük önem arz etmektedir (Balan ve ark., 2019). Bu sistemde yapilacak 3 boyutlu tasarımlar, öğrencilerin yapılacak projeyi görsel olarak incelemesine ve ekip içerisinde projeyi görsel olarak da değerlendirerek tartışmasına olanak sağlar. Açık kaynak kodlu CAD yazılımları, ücretsiz olmaları dolayısıyla, hem eğitimin verildiği kurum hem de öğrenci tarafından kolaylıkla Bilgisayar Destekli Tasarım derslerinde kullanılabilmektedir.

Yapılan çalışmalar, belirli açık kaynak kodlu CAD yazılımlarının, muadilleri olan ücretli yazılımlar gibi bu derslerde kullanılabileceğini göstermektedir (Di Angelo ve ark., 2016). Bu bildiride, yüksek öğrenim kurumları için bilgisayar destekli tasarım müfredatının açık kaynak kodlu yazılımlar ile verilebilmesine yönelik müfredat önerisi sunulmuştur. Örnek müfredat önerisi ve ders içeriği de açık kaynak lisanslama modeli ile akademinin yararına sunulmuştur.

\section{Müfredat Önerisi}

\subsection{Açık Kaynak Kodlu Yazılımlar ve Müfredatın} Gerekliliği

Günümüzde açık kaynak kodlu yazılımlar, eğitim alanında ve iş dünyasında aktif olarak kullanılmaktadır. Özellikle yazılım ve siber güvenlik gibi alanlarda açık kaynak kodlu yazılımlar, kullanıcısına sağladığı modifikasyon imkanları sebebiyle büyük öneme sahiptir. Eğitim alanında ise, bilgisayar mühendisliği, elektrik-elektronik mühendisliği ve makine mühendisliği gibi mühendislik disiplinleri, açık kaynak kodlu yazılımlardan faydalanmaktadır.

Makine mühendisliği, mekatronik mühendisliği, imalat mühendisliği ve inşaat mühendisliği gibi ağır sanayi tabanlı disiplinlerde oldukça büyük öneme sahip Bilgisayar Destekli Teknik Tasarım derslerinde, SOLIDWORKS, AUTOCAD, INVENTOR, CATIA gibi ücretli profesyonel yazılımlar kullanılmaktadır. Bahsi geçen bu yazılımlar, eğitim kurumları için özel hazırladıkları lisans modelleri ile, imalat sektöründe kullanılan lisans modellerine göre daha uygun fiyatlara lisans hizmetleri sağlamaktadır. Ancak öğrenciye tahsis edilen eğitim kurumu lisansları, belirli bir süre içerisinde ya da öğrenciliğin bitmesi durumunda son bulmaktadır. $\mathrm{Bu}$ durum ögrenciliği bitmiş olsa bile sürekli pratik yaparak kendisini geliştirmesi gereken öğrenciyi zor durumda bırakmaktadır. Kendisini geliştirmek isteyen yeni mezun ya da öğrenci lisansı sona ermiş bireyin, bahsi geçen yazılımların tam sürüm lisanslarının yüksek fiyatlarını karşılama imkanı yoktur. Bilgisayar Destekli Teknik Tasarım dersinin verildiği kurumlarda karşılaşılan bir diğer sorun ise, ders esnasında kullanılan yazılım çeşitliliğinin sınırlı olmasıdır. Sektörde her firma, ihtiyaçları doğrultusunda kendisine en uygun yazılımı seçmekte ve çalışanlarına seçtiği yazılımı kullandırmaktadır. Her ne kadar temelde aynı amaca hizmet etseler de, bahsi geçen bu yazılımlar kendi içerisinde oldukça farklılık gösterebilmektedir. Ara yüz, modüller, tasarım sistematiği ve kullanım şekli gibi kendi aralarında ciddi farklılıklar barındıran bu yazılımlar, her bir yazılım için ayrı uzmanlık gerektirmektedir. Eğitim kurumlarında ise Bilgisayar Destekli Teknik Tasarım dersinde en temel amaç, öğrenciye üç boyutlu düşünebilme kabiliyeti kazandırmaktır. Teknik resim örnekleri verilerek, öğrencinin bu teknik resimleri CAD programları ile 3D hale getirmesi beklenmektedir. Tasarıma başlamadan önce öğrenci, elinde olan 2D haldeki teknik resmi analiz etmeli ve elindeki tasarımı 3D olarak zihninde canlandırmalıdır. Yaptığı bu analiz sonras1 öğrenci, elindeki örneği kolaylıkla 3D hale getirebilmektedir. Bahsi geçen bu kabiliyeti kazandiktan sonra öğrenci, her ne kadar ara yüz olarak farkları bulunsa da, temel olarak amaçları ve kullanılan komutları aynı olan farklı CAD programlarını kısa bir alışma sürecinden sonra kullabilme yetisine sahip olacaktır. Bu kabiliyetin kazanılması için kullanılan yüksek lisans ücretlerine sahip CAD programları yerine, ücretsiz ya da çok daha uygun lisans ücretleri olan ve muadili ürünler ile neredeyse aynı kabiliyetleri bulunan açık kaynak kodlu CAD programları, öğrencinin ve kurumun maddi olarak yaşayabileceği zorlukların ve yükümlülüklerin önüne geçebilmektedir.

Bahsi geçen bu sorunların önüne geçmek adına, Bilgisayar Destekli Teknik Tasarım derslerinde açık kaynak kodlu CAD yazılımları kullanımı yaygınlaşmalıdır. Çoğu durumda ücretsiz olan ve lisans sistemi bulunmayan açık kaynak kodlu CAD yazılımları, öğrencinin yazılımı hem eğitim-öğretim hayatında hem de mezuniyet sonrasında sorunsuzca kullanabilmesine olanak sağlamaktadır. Yazılımı bu şekilde sürekli ve sorunsuz kullanabilen öğrencinin derse ve sektöre olan ilgisi artacak, aynı zamanda da yapacağı sürekli pratikler ile profesyonelliğe geçme süresi hızlanacaktır.

Bu müfredat çalışmasında FREECAD ${ }^{1}$ adlı açık kaynak kodlu CAD yazılımı kullanılmıştır. Bu yazılım, platformlardan bağımsız olarak tüm işletim sistemlerinde sorunsuz bir şekilde çalışabilmektedir. Bu sebeple, kendi kişisel bilgisayarlarında kullandıkları işletim sistemlerinden bağımsız olarak öğrenci, yazılımı sorunsuz kullanabilecektir. Bilgisayar Destekli Teknik Tasarım ders müfredatında anlatılan tüm komut ve modüllere sahip olan FREECAD, ders esnasında eğitimin verilebileceği bir platform olarak öne çıkmaktadır. Topluluk tarafından sürekli geliştirilmekte olan FREECAD, hızla gelişen yapısı ile endüstride kullanılan rakipleri ile arasındaki farkı hızlıca kapatmaktadır.

\subsection{Müfredat Önerisi}

$\mathrm{Bu}$ bölümde, yapılan müfredat çalışmasından belirli örnekler 
paylaşılarak, örneklerin değerlendirmeleri ve öğrenci üzerindeki potansiyel kazanımlarından bahsedilecektir.

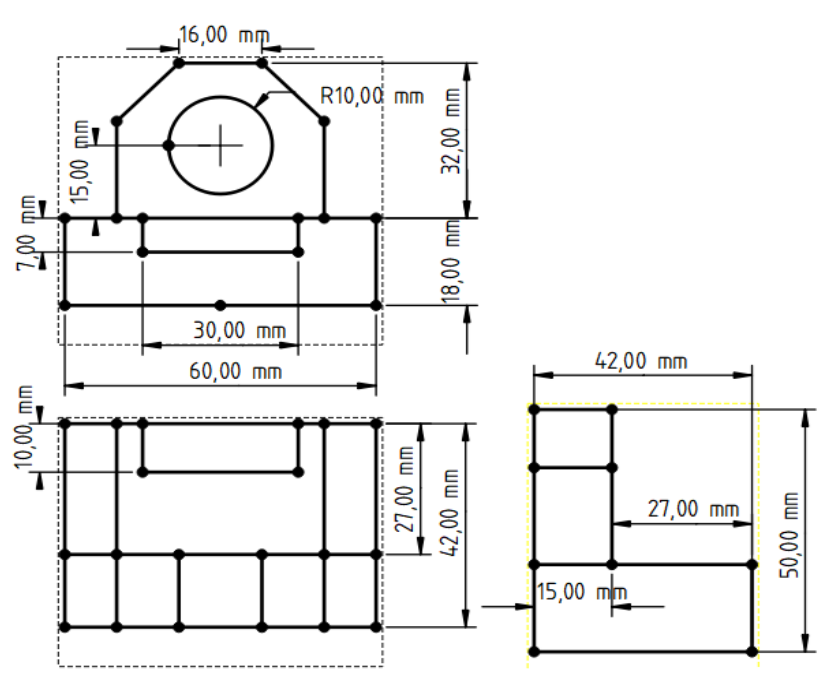

Şekil 1. 1 Teknik Tasarım Örneği 1

Şekil 1'de görülen teknik tasarım örneği, temel tasarım komutlarının kullanılması açısından temel bir örnek olarak değerlendirilebilir. Teknik resimler, tasarlanılacak olan parçanın üst,yan ve ön görünüşlerini barındıran çizimlerdir. Tasarımcı bu görünüşleri ve ölçülendirmeleri kullanarak çizimi 3D hale getirir. Teknik resim kağıdının sağ altında bulunan antet kısımlarında, çizimi yapan kişinin ismi, çizimin ölçeklendirmesi ve tasarlanacak olan parçanın imal edileceği malzeme gibi başlıklar bulunur

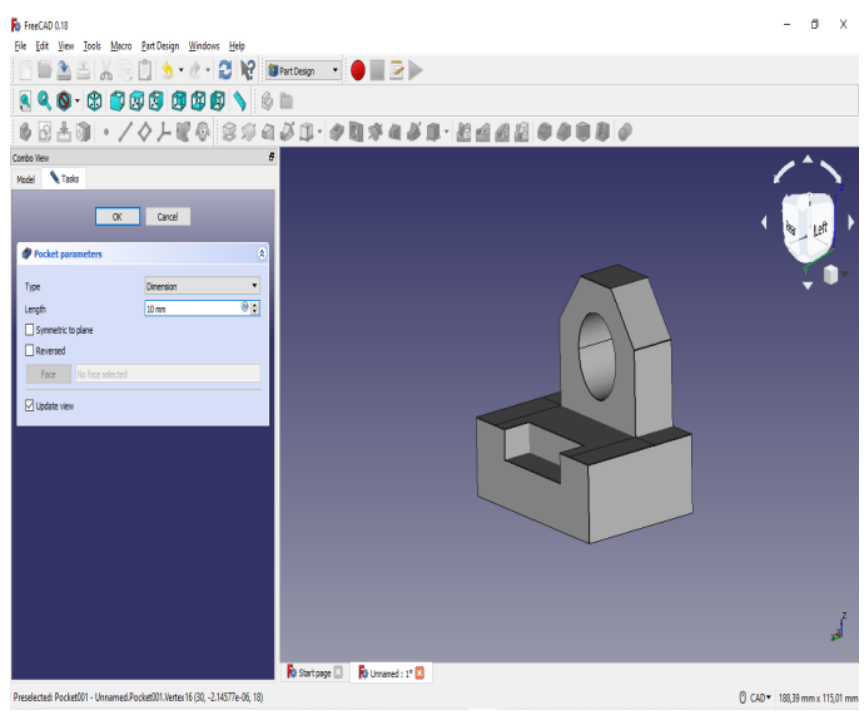

Şekil 2. Teknik Tasarım Örneği 1'in FREECAD'de Uygulanmas1

Şekil 1 de gösterilen teknik tasarım örneği, Şekil 2 de'de görülebileceği üzere kolaylıkla FREECAD yazılımında uygulanmıştır. $\mathrm{Bu}$ örnek ile öğrenciler, navigasyon araçları, iki boyutlu çizim, katı oluşturma ve delik delme komutları üzerinde kazanımlar elde edebilir. Bu örnek, öğrencilerin temel olarak 3 boyutlu düşünebilme kabiliyetlerine hitap etmesi, temel katı komutlarının kullanılması ve teknik resminin kolay analiz edilebilmesi dolayısıyla başlangıç seviyesinde bir örnek olarak değerlendirilebilir.
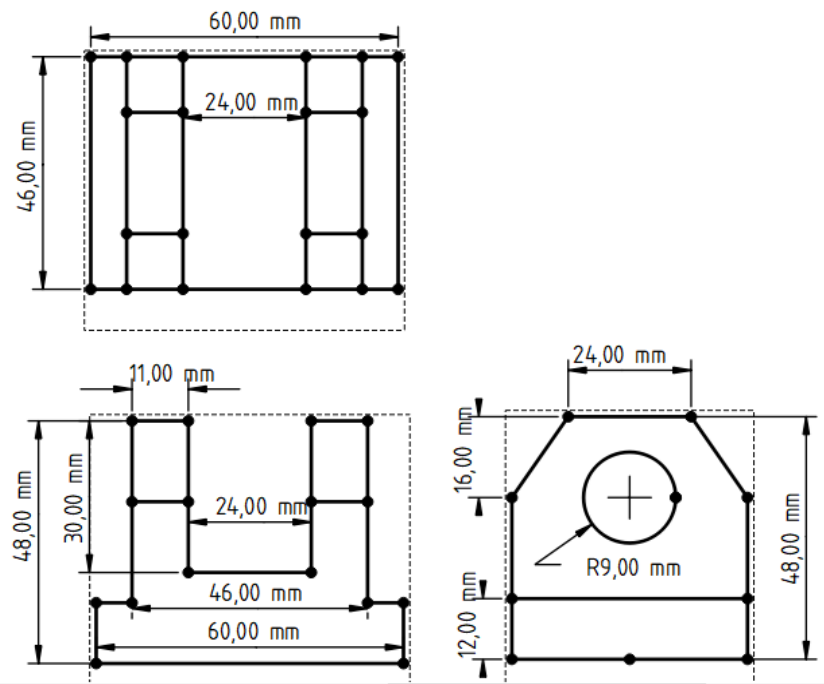

Şekil 3. Teknik Tasarım Örneği 2

Şekil 3'te de görülebilen 2 numaralı teknik tasarım örneği, yüzey çizimlerinin aktif kullanımı, farklı görünüş ve eksenlerde çizimi analiz edebilme ve çizim yapabilme kabiliyeti gerektirdiğinden dolay1, orta düzey bir teknik tasarım örneği olarak değerlendirilebilir.

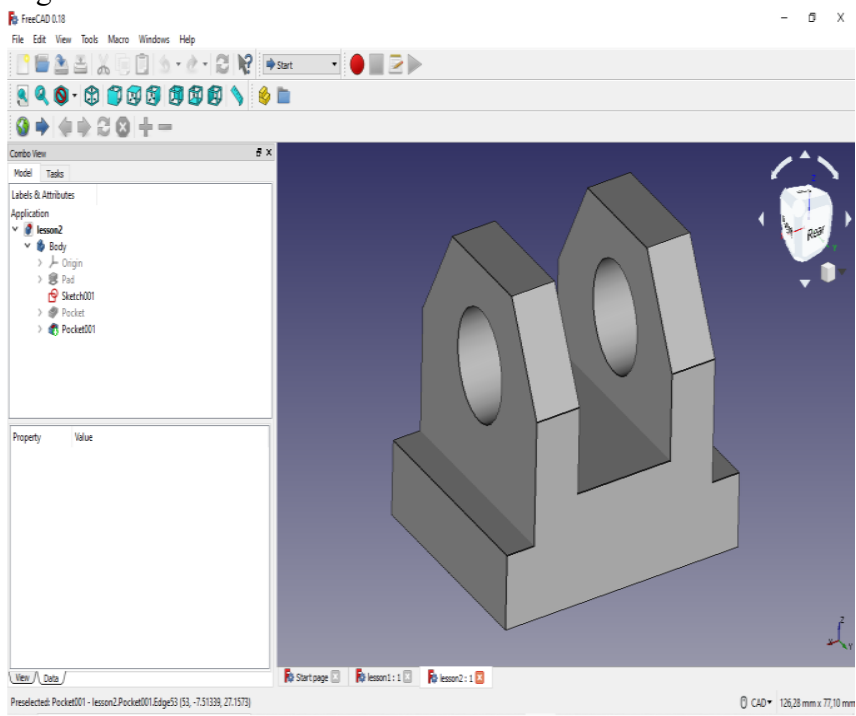

Şekil 4. Teknik Tasarım Örneği 2'nin FREECAD'de Uygulanması

Şekil 3'de görülen teknik tasarım örneği, Şekil 4'te görülebileceği üzere başarılı bir şekilde FREECAD'de uygulanmıştır. Bu örnek ile öğrenciler, farklı yüzeylerde çizim yapabilme ve 3D çizimleri 2 boyutlu şekilde düşünebilme kabiliyetini kazanır.

Bilgisayar Destekli Teknik Tasarım derslerinde öğretilen en önemli modüllerden biri de montaj modülleridir. Endüstride de hali hazırda oldukça fazla kullanılan montaj modülleri, işverenler tarafından işe alım süreçleri esnasında aday değerlendirmelerinde önemli bir yere sahiptir. Montaj modülleri, gerek yazılımdaki kompleks komutları kullanabilme becerisi gerek de montaj1 yapılacak olan sistemi düzgün analiz edebilme kabiliyeti gerektirdiğinden dolayı, Bilgisayar Destekli Teknik Tasarım derslerindeki ileri düzey 
uygulamalardan sayılmaktadır. Şekil 5'te görülebileceği üzere, Bilgisayar Destekli Teknik Tasarım derslerinde de oldukça kullanılan bir örnek olan universal mafsalın montajı, FREECAD yazılımı ile rahatlıkla yapılabilmektedir. FREECAD yazılımı sayesinde öğrencinin yapacağı montaj uygulamaları, öğrencinin tümevarım bakış açısını kazanmasına yardımcı olacaktır. Çalışılan sistemin tek bir parçasından ziyade tümüne hakim olma zorunluluğu gerektiren montaj, yapılan bu uygulamalar sayesinde öğrencinin sektörde işe alım süreçlerinde olası diğer adaylar arasında bir adım öne çıkmasını sağlayacaktır.

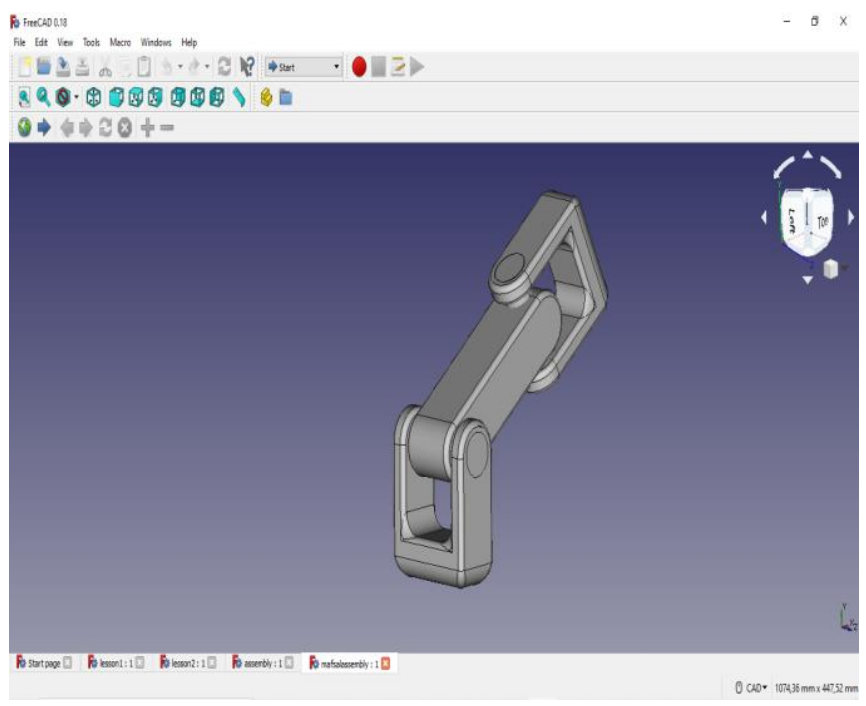

Şekil 5. Universal Mafsalın FREECAD ile Montajı

\section{Sonuçlar}

Günümüzde bilgi erişimin önündeki engellerin kalkması ile gün geçtikçe kullanımı artan açık kaynak kodlu yazılımlar, çok farklı sektörlerde kullanılmaya başlanmıştır. Kullanıcılar tarafindan sürekli geliştirilen bu yazılımlar, sektörde kullanılan muadil ürünler ile arasındaki farkı gün geçtikçe azaltmaktadır. Eğitim alanında da, lisanslı ürünlerin fiyatları ve kullanım şartlarından doğan bazı durumlar,hem eğitmene hem de öğrenciye zorluklar yaşatmaktadır. Açık kaynak kodlu yazılımlar sayesinde bu zorlukların önüne geçilebilmektedir. Bu bildiride, çeşitli lisans ve önlisans programlarında aktif olarak işlenen Bilgisayar Destekli Teknik Tasarım dersinin, açık kaynak kodlu yazılımlar ile verilecebileceği bir müfredat önerisi sunulmuştur. Gelecek çalışmalarda örnek sayısı ve çeşitliliği artırılacak, örneklerin içerikleri geliştirilerek çalışma, eğitim kurumlarında kolaylıkla Bilgisayar Destekli Teknik Tasarım dersinde uygulanabilir hale getirilecektir.

\section{Kaynaklar}

GNU General Public Licence Version 3. Free Software Foundation. URL: https://www.gnu.org/licenses/gpl-3.0.html

Pearce, J. M., Blair, C. M., Laciak, K. J., Andrews, R., Nosrat, A., Zelenika-Zovko, I. (2010) .3-D Printing of Open Source Appropriate Technologies for Self-Directed Sustainable

Development. Journal of Sustainable Development Vol. 3, No. 4;

Junk, S., Kuen, C.. (2016) . Review of Open Source and Freeware CAD Systems for Use with 3D- Printing. Procedia CIRP Volume 50. 430-435

Fang-Yu, S., Jen-Chin, Tsai., Morton, D., Wei-Shao, Lin. (2019). Use of an open-source CAD software program and additive manufacturing technology to design and fabricate a definitive cast for retrofitting a crown to an existing removable partial denture. Journal of Prosthetic Dentistry

Vasques, M. T., Mori, M., Lagana, D. C. (2019) Threedimensional printing of occlusal devices for temporomandibular disorders by using a free CAD software program: A technical report .Journal of Prosthetic Dentistry

Tachibana, K., Oka, K. (2011)Design of small electric generator by free CAD and analysis software. The 20th MAGDA Conference in Pacific Asia, November 14-16, 2011, Kaohsiung, Taiwan

Jin-Yang, L., Long, G., Hu-Shan, X., Korepanova, N., Wei, J., Xin, S., Yan-Lei, Z., Rui, Yu. (2018) .FreeCAD based modeling study on MCNPX for accelerator driven system. Progress in Nuclear Energy Volume 107. Pages 100-109

Robertson, D., Allen, T, J. (1991) CAD System Use and Engineering Performance in Mechanical Design .Massachusetts Institute of Technology January

Balan, L., Timber, Y., Mehrtash, M. .(2019) .Problem-Based Learning Strategy for CAD Software Using Free-Choice and Open-Ended Group Projects . Procedia Manifacturing Volume 32, Pages 339-347

Di Angelo, P., Leali, F., Di Stefano, P. (2016).Can Open-Source 3D Mechanical CAD Systems Effectively Support University Courses? . International Journal of Engineering Education 